DOI: https://doi.org/10.47405/mjssh.v7i1.1250

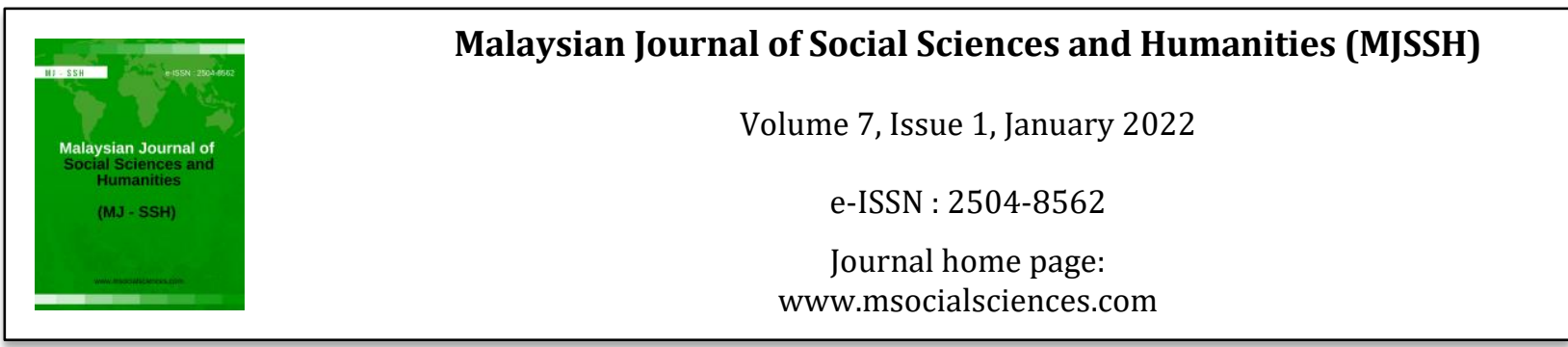

\title{
Pembelajaran Berasaskan Inkuiri dalam Meningkatkan Kemahiran Literasi Sains dan Pencapaian Murid menerusi Persekitaran Pembelajaran dalam Talian
}

\author{
Nurul Farhana Jumaat ${ }^{1}$, Yazid Saupian', Noor Hidayah binti Che Lah' \\ 1Sekolah Pendidikan, Universiti Teknologi Malaysia (UTM), Malaysia \\ ${ }^{2}$ Fakulti Seni, Komputeran dan Industri Kreatif, Universiti Pendidikan Sultan Idris (UPSI), Malaysia
}

Correspondence: Nurul Farhana Jumaat (nfarhana@utm.my)

\begin{abstract}
Abstrak
Kajian ini bertujuan untuk mengkaji kesan pembelajaran berasaskan inkuiri melalui model 5E terhadap kemahiran literasi Sains dan pencapaian murid menerusi persekitaran pembelajaran dalam talian iaitu aplikasi Google Classroom. Reka bentuk kajian ini adalah berbentuk kuantitatif iaitu kajian praeksperimental satu kumpulan pra dan pasca-ujian. Sampel kajian ini terdiri daripada 30 orang murid Tahun 6 yang dipilih melalui teknik persampelan bertujuan manakala proses pengumpulan data pula mengambil masa selama empat minggu. Data kajian diperoleh melalui instrumen seperti borang soal selidik, borang senarai semak dan ujian pra dan pasca pencapaian Sains yang merangkumi topik Daya Geseran. Data kemudiannya dianalisis menggunakan analisis deskriptif dan analisis inferensi. Analisis inferensi melibatkan Ujian Wilcoxon Signed Rank menggunakan perisian SPSS. Dapatan kajian menunjukkan tahap kesediaan murid adalah berada pada tahap yang memuaskan di mana majoriti pelajar bersetuju bahawa pembelajaran dalam talian memberi manfaat kepada mereka. Dapatan kajian juga mendapati kemahiran literasi Sains murid adalah memberangsangkan di mana hampir kesemua murid mempunyai kemahiran literasi Sains yang memuaskan setelah melalui persekitaran pembelajaran berasaskan inkuiri menerusi aplikasi Google Classroom. Akhir sekali, dapatan kajian mendapati bahawa terdapatnya perbezaan yang signifikan diantara markah purata pra dan pasca ujian dalam pencapaian Sains murid. Kesimpulannya, melalui kajian ini, pengkaji mendapati pembelajaran berasaskan inkuiri melalui model 5E dapat meningkatkan kemahiran dan pencapaian literasi Sains pelajar melalui persekitaran pembelajaran dalam talian iaitu aplikasi Google Classroom.
\end{abstract}

Kata kunci: pembelajaran berasaskan inkuiri, kemahiran literasi Sains, pembelajaran dalam talian

\section{Inquiry-Based Learning in Enhancing Students' Science Literacy Skills and Achievement in Online Learning Environment}

\begin{abstract}
This study aims to examine the effect of inquiry-based learning through the 5E model on students' Science literacy skills and achievement through the online learning environment which is Google Classroom application. The design of this study is quantitative, that is, a pre-experimental study of a pre- and post-test group. The sample of this study consists of 30 Year 6 students who were selected through purposive sampling technique while the data collection process took about four weeks. Data were obtained through instruments like questionnaire, checklist forms and pre and post achievement test covering the topic of Frictional Forces. Data were then analyzed using the descriptive analysis and inferential analysis. The inferential analysis test involved a Wilcoxon Signed Rank test by using SPSS
\end{abstract}


software. The findings of the study showed that the level of readiness of students is at a satisfactory level where majority of students agree that online learning benefits them. The findings of the study also found that students' Science literacy skills are encouraging where most of the students poses an encouraging Science literacy skills after going through an inquiry-based learning environment through the Google Classroom application. Finally, the findings of the study also found that there was a significant difference between the pre and post-test average scores in students' Science achievement. In conclusion, through this study, researchers found that inquiry-based learning through $5 \mathrm{E}$ model can improve students' Science literacy skills and achievement through the online learning environment which is Google Classroom application.

Keywords: inquiry-based learning, Science literacy skills, online learning

\section{Pengenalan}

Subjek Sains merupakan salah satu subjek yang dititik beratkan oleh mantan Perdana Menteri Malaysia iaitu Tun Dr Mahathir bin Mohamad. Menurut beliau, ketika memperkenalkan pengajaran dan pembelajaran bahasa Inggeris (PPSMI) pada tahun 2003, menguasai Sains adalah salah satu prasyarat utama untuk berdaya saing di peringkat global. Oleh hal yang demikian, Pusat Perkembangan Kurikulum pada tahun 2002, telah mengembangkan kurikulum pendidikan subjek Sains kebangsaan untuk membolehkan pelajar menyedari potensi diri dengan memperoleh pengetahuan dan berkomunikasi. Menyedari akan kepentingan ini, murid seawal di peringkat sekolah rendah perlu dilengkapkan dengan kemahiran literasi Sains yang baik. Kemahiran literasi Sains ini dipengaruhi oleh beberapa faktor, antaranya adalah pendedahan kepada murid menerusi pembelajaran yang membolehkan mereka untuk meneroka ilmu pengetahuan. Murid juga dapat mengembangkan konsep dan proses Sains yang dipelajari jika guru memberikan bimbingan secara berterusan (Yaumi, Wisanti \& Admoko, 2017).

Seperkara yang penting adalah, guru perlu menetapkan strategi pembelajaran tertentu agar proses pembelajaran dapat berjalan dengan lebih teratur. Terdapat pelbagai jenis strategi pembelajaran telah diperkenalkan untuk diamalkan dalam proses pembelajaran antaranya ialah kaedah pembelajaran berpusatkan pelajar (Sidek \& Hashim, 2016). Kaedah pembelajaran berpusatkan pelajar memerlukan pelajar untuk memainkan peranan mereka dengan melibatkan diri secara aktif dalam sesi pembelajaran (Maria, Samsilah \& Tajulripin, 2014). Tambahan pula, kaedah pembelajaran berpusatkan pelajar yang digabungkan dengan penggunaan teknologi dapat menjadikan sesebuah penyampaian pembelajaran lebih menarik dan berkesan (Huba \& Freed, 2000). Ini adalah kerana, dengan bantuan teknologi, proses pembelajaran dapat menyokong tugasan yang perlu dilakukan secara individu mahu pun secara berkumpulan (Sidek \& Hashim, 2016; Huba \& Freed, 2000).

Pendekatan pembelajaran berasaskan inkuiri merupakan salah satu kaedah pembelajaran berpusatkan pelajar dan kaedah ini adalah sangat efektif untuk diterapkan bagi menggalakkan penglibatan aktif pelajar dalam pembelajaran (Zhao, Wardesk, McGuire \& Cook, 2014). Pendekatan inkuiri dilihat dapat membantu pelajar dalam usaha menggalakkan pembelajaran kendiri (Atkinson \& Hunt, 2008). Seperti contoh dalam kajian yang dijalankan oleh Rozali \& Abd Halim (2020), membuktikan bahawa kaedah pembelajaran berasaskan inkuiri adalah sangat berkesan diterapkan dalam aktiviti pembelajaran. Begitu juga dalam kajian yang dijalankan oleh Summerlee dan Murray (2010) membuktikan bahawa penerapan pembelajaran berasaskan inkuiri dalam subjek Sains berupaya meningkatkan motivasi pelajar, melatih pelajar berfikir secara analitik dan memperkukuh kemahiran kognitif mereka.

Tidak dinafikan, situasi pembelajaran pada masa kini lebih terarah kepada penggunaan teknologi, dimana akses kendiri, pembelajaran secara kendiri dan juga pendidikan kendiri amat diperlukan (Nordin \& Daud, 2020). Justeru, landskap pendidikan kini berubah kepada pembelajaran secara dalam talian seiring dengan pembangunan jalur lebar yang menyebabkan pendidikan pada masa kini tertumpu kepada penggunaan teknologi (Raja Ismail \& Ismail, 2018). Ditambah pula dengan situasi yang menggusarkan dimana pada akhir tahun 2019, dunia dikejutkan dengan wabak COVID-19, ia sekaligus 
menjejaskan aktiviti pembelajaran dan pengajaran (PdP) dimana guru dan pelajar tidak dapat lagi bersemuka, dan PdP perlu dilaksanakan sepenuhnya secara dalam talian. Antara platform digital yang digunakan oleh para guru adalah seperti aplikasi Whatsapp, Google Classroom, Zoom, Webex, YouTube, dan banyak lagi aplikasi digital yang lain telah dimanfaatkan dengan sewajarnya.

Memahami akan situasi semasa dan kepentingan kemahiran dan pengetahuan Sains murid dalam mendepani era globalisasi, kajian ini telah membangunkan persekitaran pembelajaran berasaskan inkuiri iaitu model 5E menerusi platform Google Classroom untuk mengenal pasti tahap kemahiran literasi Sains murid serta mengkaji kesan persekitaran pembelajaran berasaskan inkuiri terhadap pencapaian Sains murid melalui medium pengajaran dan pembelajaran dalam talian ke atas murid tahun enam di sebuah sekolah di daerah Johor Bahru.

\section{Objektif Kajian}

Kajian ini mengandungi tiga objektif utama iaitu:

i. Mengenal pasti kesediaan murid dalam pembelajaran Sains secara dalam talian.

ii. Mengenal pasti kemahiran literasi Sains murid dalam persekitaran pembelajaran dalam talian.

iii. Mengkaji kesan pembelajaran berasaskan inkuiri terhadap pencapaian Sains murid dalam persekitaran pembelajaran dalam talian

\section{Kerangka Konsep}

Kerangka konsep kajian menerangkan secara umum tentang kajian yang dilaksanakan. Rajah 1 menunjukkan kerangka konsep kajian ini.

\section{Rajah 1: Kerangka konsep kajian}

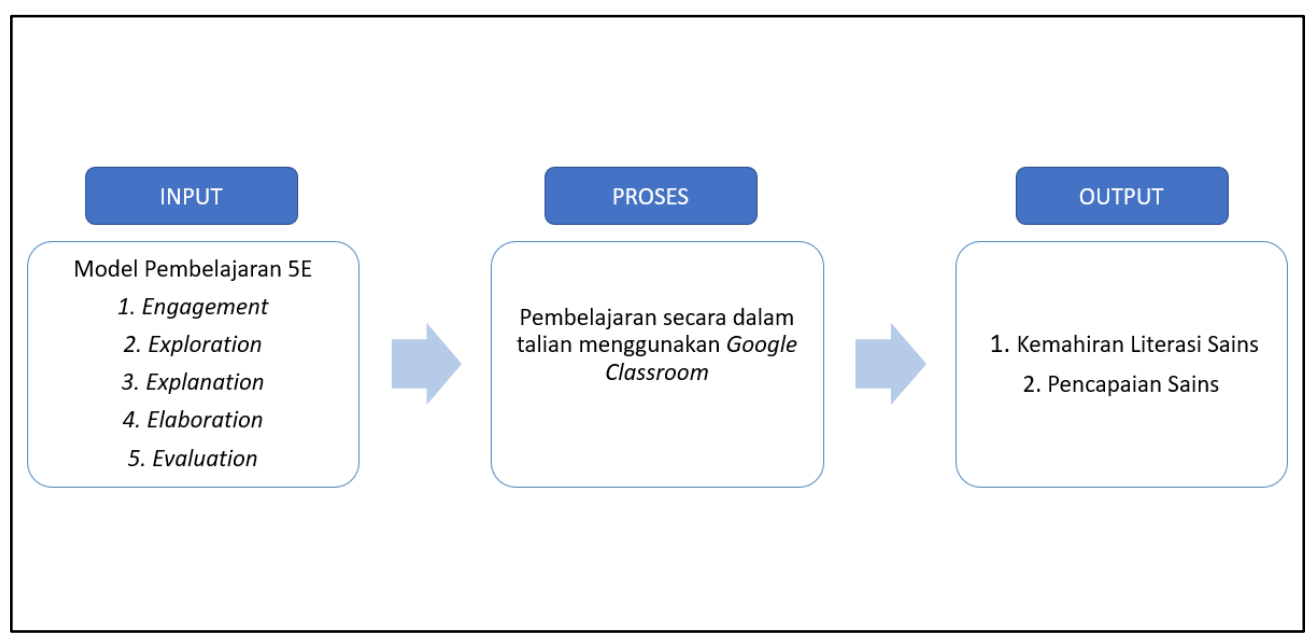

Kerangka konsep kajian mengklasifikasikan variabel yang terdapat di dalam kajian ini kepada tiga kategori utama iaitu input, proses dan output. Input yang terlibat dalam kajian ini adalah model pembelajaran berasaskan inkuiri dimana guru mengaplikasikan model 5E dalam pembelajaran. Model 5E ini diperkenalkan oleh Baybee et al. (2006). Pengkaji menggunakan kelima -lima elemen di dalam pembangunan aktiviti persekitaran pembelajaran dalam talian menerusi aplikasi Google Classroom kerana model yang digunakan dapat membantu murid meningkatkan pemahaman isi kandungan pembelajaran yang terperinci melalui persekitaran pembelajaran yang aktif.

Model Pembelajaran Inkuiri 5E telah di asaskan oleh Baybee et al. (2006), yang mempunyai ciri-ciri pembelajaran berasaskan inkuiri yang diterangkan dengan lebih lanjut di bawah: 
Fasa penglibatan adalah fasa set induksi untuk menarik perhatian murid terhadap topik pembelajaran yang akan dipelajari. Pada peringkat ini guru menyediakan bahan bantu mengajar yang menarik dan tersusun untuk mencetus idea murid berkaitan dengan topik pembelajaran yang akan dipelajari, menyoal murid, serta membuat demonstrasi berkaitan topik yang dipelajari.

\section{ii. Penerokaan (Exploration)}

Pendekatan fasa ini adalah untuk menarik minat murid untuk melakukan penelitian seperti mengumpul data, memerhati, mencuba serta meneka. Murid akan berusaha memahami kandungan pembelajaran melalui pengetahuan dan pengalaman mereka sendiri.

\section{iii. Penerangan (Explanation)}

Pada fasa ini guru berusaha menggalakkan murid memberikan penerangan berdasarkan pemerhatian yang telah dilakukan, dan murid diminta menunjukkan hasil kerja mereka. Guru akan menggalakkan murid menerangkan konsep berdasarkan pengetahuan yang mereka ada beserta mendengar pendapat dari rakan mereka sendiri.

\section{iv. Penghuraian (Elaboration)}

Fasa ini adalah fasa dimana murid di beri ruang dan peluang untuk memahami permasalahan yang mereka hadapi serta dapat memberikan hujah-hujah yang baik untuk mempertahankan kenyataan mereka sendiri dan pada masa yang sama dapat berkongsi idea dengan rakan mereka sendiri.

\section{v. Penilaian (Evaluation)}

Fasa terakhir adalah fasa penilaian dimana memerlukan murid menguatkan kefahaman mereka terhadap ilmu pengetahuan yang terbentuk seperti boleh menjawab soalan yang dikemukakan oleh guru, membuat generalisasi serta boleh menterjemah pembelajaran yang telah dilalui.

Proses pula melibatkan proses pengajaran dan pembelajaran menerusi penggunaan aplikasi atau platform Google Cassroom. Aplikasi ini disediakan oleh pihak Gooogle yang bersifat mesra pengguna. Pelbagai ciri yang menarik dalam aplikasi ini dimana aplikasi ini boleh dilayari dengan menggunakan komputer ataupun telefon bimbit. Proses pengajaran dan pembelajaran Sains dalam talian ini lebih mudah kerana pelbagai aktiviti pembelajaran boleh dimasukkan seperti guru boleh menghantar tugasan kepada murid dengan lebih tersusun dan rapi dan guru boleh menetapkan tarikh dan penerimaan tugasan oleh murid. Selain it, aktiviti kuiz boleh dimasukkan dalam aplikasi ini yang menggalakkan murid menyertai aktiviti pembelajaran yang menyeronokkan, murid juga boleh berinteraksi dengan guru seperti bertanyakan soalan tentang topik yang dipelajari pada bila-bila masa serta murid tidak berasa malu dan kekok kerana mereka juga boleh bertanya secara peribadi. Dalam aplikasi ini juga guru boleh berkongsi bahan bantu belajar dengan murid seperti memasukkan video pembelajaran dari medium Youtube, menyediakan soalan berbetuk google form dan guru serta murid boleh menyimpan bahan pembelajaran tersebut di dalam folder yang disediakan di dalam aplikasi ini.

Elemen terakhir adalah output, dimana pengkaji menilai kemahiran literasi Sains murid serta menganalisis hasil pencapaian murid dalam mata pelajaran Sains. Diharapkan pada peringkat ini pencapaian mata pelajaran Sains dapat dipertingkatkan hasil daripada pengintegrasian pembelajaran berasaskan inkuiri secara dalam talian.

\section{Sorotan Literatur}

\section{Penekanan dalam pengajaran dan pembelajaran Sains KSSR}

Pendekatan Kurikulum Sains KSSR di susun secara rapi supaya guru berpeluang untuk mewujudkan suasana pengajaran dan pembelajaran yang harmoni bermanfaat dan menarik kepada murid. Untuk memastikan setiap murid menunjukkan peningkatan dalam penerimaan konsep dan kemahiran yang dipelajari. Untuk mengorak peralihan ke bidang pembelajaran atau topik yang lain, beberapa penekanan perlu diambil antaranya: 
i. Mengaplikasikan pengetahuan dan kemahiran secara kritis, kreatif dan analitis bagi membuat keputusan dan menyelesaikan masalah.

ii. Menyebarluaskan kefahaman mengenai fakta dan konsep asas sains.

iii. Meningkatkan daya kreativiti murid.

iv. Murid boleh memahami asas yang dipelajari dalam bidang yang dipelajari

Dalam kajian ini pengkaji, pengkaji menjalankan kajian bagi topik Daya Geseran tahun 6 di bawah tema Sains fizikal.

\section{Kemahiran literasi Sains}

Pusat Perkembangan Kurikulum (1997) mentafsirkan kemahiran literasi sains adalah usaha seseorang mencari resolusi penyelesaian yang rasional berkaitan dengan fenomena alam semula jadi. Penerangan ini membuktikan ia merangsang dan memberi kefahaman tentang wujudnya undang-undang, prinsip, peraturan serta perkaitan dengan fenomena alam semula jadi. Pendidikan Sains adalah bermatlamat menjadikan seorang murid itu mendapat kefahaman dari segi prinsip sains dan dapat menghubungkan kefahaman saintifik tersebut dengan pengalaman seharian mereka. Dalam bidang pembelajaran Sains, kemahiran literasi Sains sering dikaitkan dengan kurangnya kefahaman dan pengetahuan Sains serta pencapaian mereka berada pada peringkat yang lemah. Acap kali kedengaran konsepsi murid berada dalam tahap yang lemah berdasarkan pengalaman dan pemerhatian dalam kehidupan harian mereka.

\section{Pembelajaran berasaskan inkuiri}

Menurut Rozali \& Abd Halim (2020), perkataan inkuiri membawa maksud proses mencari, meneroka dan menyiasat masalah serta menggunakan deria dan kognisi. Prayogi, Yuanita dan Wasis (2018) pula berpendapat pendekatan PBIK melibatkan proses inkuiri, aspek pengetahuan sedia ada, motivasi, dan pemikiran kritis murid-murid dilibatkan secara aktif dalam sesi perbincangan dan dapat meneroka aktiviti yang diberikan oleh guru. Inkuiri juga dikatakan sebagai proses kognitif, afektif dan psikomotor di mana mental murid akan terbina semasa melakukan aktiviti inkuiri.

Murid yang memberikan cadangan ataupun pendapat dan membuat penjelasan berdasarkan bukti yang diperoleh selepas melakukan penerokaan. Selain itu, murid juga membuat perkaitan antara penjelasan mereka dengan pengetahuan dan teori saintifik yang telah mereka pelajari. Pendapat Ganesan et al. (2020) mengaitkan bahawa kaedah inkuiri adalah perasaan rasa ingin tahu di kalangan individu mengenai sesuatu dan menghendaki murid mempersoalkan kebenaran dan ketepatan maklumat yang diperoleh. Di samping itu, pelajar boleh berkomunikasi dan menjelaskan hasil penemuan mereka. Pembelajaran berasaskan inkuiri merupakan satu konsep pembelajaran yang berpusat murid kerana murid bergiat aktif membentuk konsep dan membuat generalisasi pengetahuan baharu.

Kajian-kajian berkaitan penggunaan kaedah inkuiri telah banyak dikaji oleh pengkaji sama ada di dalam atau luar negara. Menurut Umar dan Maswan (2007) menyatakan inkuiri berupaya membantu dalam pemindahan maklumat secara aktif dan mempertingkatkan kemahiran berfikir murid. Maidinshah (2004), mendapati kaedah inkuiri mempunyai daya penarik sebagai medium pengajaran yang sangat efektif.Dalam pembelajaran berasaskan inkuiri, guru juga bertindak sebagai fasilitator untuk membimbing dan mengurus pelajar sehingga mereka memperoleh pengetahuan (McLoughlin, 2009). Di samping itu, Hmelo-Silver, Duncan dan Chinn (2007) juga menyokong bahawa tugas guru perlu diubah menjadi fasilitator. Mereka menyediakan persekitaran untuk pelajar membuat keputusan dan bahkan melatih pelajar untuk menyelesaikan masalah.

\section{Model inkuiri 5E}

Model Pembelajaran Inkuiri 5E atau 5E Instructional Model merupakan model yang telah diperkenalkan oleh pengkaji barat iaitu Bybee et al. (2006). Model ini berfungsi sebagai proses peningkatan tahap pelajar Sains di Colorado, USA. Model ini juga dibina berdasarkan teori pembelajaran konstruktivisme yang menggunakan pendekatan berasaskan inkuiri (Nor Puteh \& 
Naswatheen, 2013). Model ini merangkumi 5 fasa dalam proses pengajaran dan pembelajaran iaitu fasa penglibatan (engagement), penerokaan (exploration), penerangan (explaination), penghuraian (elaboration), dan penilaian (evaluation). Model 5E ini tidak seharusnya dijalankan serentak sewaktu pengajaran dan pembelajaran, ia boleh dijalankan secara berasingan mengikut situasi iaitu mengikut tahap kemampuan murid itu sendiri.

\section{Metod Kajian}

\section{Reka bentuk kajian}

Kajian yang dijalankan oleh pengkaji adalah berbentuk kajian kuantitatif menggunakan kaedah pra dan pasca-ujian satu kumpulan (one group pre and post-test design). Tiada kumpulan rawatan yang terlibat kerana pengkaji ingin mengelakkan adanya komunikasi yang mungkin berlaku antara kumpulan kawalan dan rawatan. Data kuantitatif yang diperoleh menerusi soal selidik, borang senarai semak dan ujian pencapaian dianalisis secara deskriptif dan inferensi dimana data tersebut dipersembahkan dalam bentuk jadual dan nilai statistik.

\section{Populasi dan sampel kajian}

Populasi bagi kajian ini adalah seramai 156 orang murid tahun enam. Walau bagaimanapun, hanya 30 orang murid sahaja yang terlibat dalam kajian ini di mana sampel telah dipilih menggunakan teknik persampelan bertujuan. 30 orang sampel ini terdiri daripada murid dari kelas yang sama yang mempunyai pengetahuan asas Sains serta mempunyai kemahiran komputer yang setara.

\section{Instrumen kajian}

Terdapat 3 instrumen yang digunakan dalam kajian ini iaitu, (i) borang soal-selidik untuk mengukur tahap kesediaan murid sewaktu pembelajaran dalam talian, (ii) borang senarai semak untuk mengukur kemahiran literasi Sains murid dan (iii) ujian pra dan ujian pasca untuk mengukur pencapaian Sains murid setelah menjalani persekitaran pembelajaran berasaskan inkuiri secara dalam talian. Borang soalselidik untuk mengukur tahap kesediaan murid sewaktu pembelajaran dalam talian diadaptasi dari soalselidik hasil dari kajian yang dijalankan oleh Said, Mohd Shariff dan Abd Rahman (2017) disesuaikan dengan sampel kajian ini, soal-selidik ini menggunakan Skala Likert tiga mata iaitu STS, (Sangat Tidak Setuju), TS (Tidak setuju), S mewakili Setuju.

Bagi borang senarai semak untuk mengukur kemahiran literasi Sains, guru diminta untuk membuat pemerhatian sepanjang intervensi berlangsung dan melengkapkan borang senarai semak yang telah disediakan oleh pengkaji. Antara item yang terkandung di dalam senarai semak tersebut termasuklah, a) "Adakah murid faham akan konsep Sains yang dipelajari?", b) "Semasa melakukan aktiviti penyiasatan Sains adakah murid menggunakan pengetahuan sedia ada mereka?" dan c) "Dalam aktiviti pembelajaran Sains, adakah murid menyertai sesi soal jawab yang dikemukakan oleh guru?". Akhir sekali adalah instrumen ujian pra dan pasca merupakan ujian yang diberikan sebelum dan selepas intervensi untuk mengukur pencapaian murid. Kandungan soalan adalah meliputi topik Daya Geseran. Soalan ujian pencapaian ini mengandungi 2 bahagian utama iaitu 30 soalan berbentuk objektif manakala 7 soalan lagi berbentuk subjektif. Markah penuh ujian pencapaian ini adalah sebanyak 40 markah. Kesahan instrumen-instrumen kajian ini telah dilakukan oleh 2 orang pakar bidang Sains, manakala skala kebolehpercayaan instrumen ujian pencapaian adalah agak tinggi iaitu sebanyak 0.768 . 


\section{Hasil Kajian}

\section{Analisa kesediaan murid menerusi persekitaran pembelajaran dalam talian}

Persoalan kajian pertama adalah untuk mengkaji tahap kesediaan murid dalam pembelajaran Sains secara dalam talian. 30 orang murid Tahun 6 telah terlibat dalam kajian ini dimana seramai 53\% responden adalah murid lelaki manakala $47 \%$ responden adalah terdiri dari murid perempuan. Jadual 1 menunjukkan dapatan bagi tahap kesediaan murid dalam pembelajaran Sains dalam talian.

Jadual 1: Statistik tahap kesediaan murid dalam pembelajaran Sains dalam talian

\begin{tabular}{|c|c|c|c|c|}
\hline No & Item soalan & $\begin{array}{l}\text { STS } \\
\%\end{array}$ & $\begin{array}{l}\text { TS } \\
\%\end{array}$ & $\begin{array}{l}\mathrm{S} \\
\%\end{array}$ \\
\hline 1 & $\begin{array}{l}\text { Pembelajaran dalam talian di sekolah membantu } \\
\text { pembelajaran sains }\end{array}$ & $23 \%$ & $33 \%$ & $43 \%$ \\
\hline 2 & $\begin{array}{l}\text { Pembelajaran dalam talian memudahkan } \\
\text { interaksi }\end{array}$ & $7 \%$ & $27 \%$ & $67 \%$ \\
\hline 3 & $\begin{array}{l}\text { Pembelajaran dalam talian membantu } \\
\text { berinteraksi secara lebih berkesan }\end{array}$ & $6.5 \%$ & $6.5 \%$ & $87 \%$ \\
\hline 4 & $\begin{array}{l}\text { Saya percaya pembelajaran dalam talian } \\
\text { memberi manfaat kepada saya }\end{array}$ & $0 \%$ & $37 \%$ & $63 \%$ \\
\hline 5 & $\begin{array}{l}\text { Latihan yang diberikan dalam pembelajaran } \\
\text { dalam talian membantu saya untuk memahami } \\
\text { topik yang diberi }\end{array}$ & $0 \%$ & $0 \%$ & $100 \%$ \\
\hline 6 & $\begin{array}{l}\text { Pembelajaran dalam talian akam memberi fokus } \\
\text { kepada saya dalam pembelajaran }\end{array}$ & $0 \%$ & $20 \%$ & $80 \%$ \\
\hline 7 & $\begin{array}{l}\text { Pembelajaran saya begitu menyeronokkan } \\
\text { dalam pembelajaran dalam talian }\end{array}$ & $17 \%$ & 0 & $83 \%$ \\
\hline 8 & $\begin{array}{l}\text { Pembelajaran dalam talian membantu saya } \\
\text { meningkatkan pencapaian sains }\end{array}$ & $0 \%$ & $0 \%$ & $100 \%$ \\
\hline 9 & $\begin{array}{l}\text { Guru banyak membantu saya dalam } \\
\text { pembelajaran sains }\end{array}$ & $10 \%$ & $20 \%$ & $70 \%$ \\
\hline 10 & $\begin{array}{l}\text { Saya mudah bertanya dengan guru dengan } \\
\text { menggunakan pembelajaran dalam talian }\end{array}$ & $0 \%$ & $23 \%$ & $77 \%$ \\
\hline
\end{tabular}

Dapatan dari soal selidik ini mendapati bahawa keseluruhan murid bersetuju bahawa pembelajaran dalam talian membantu meningkatkan pencapaian mereka dalam subjek Sains, dan latihan yang diberikan guru membantu mereka memahami topik pembelajaran. Ini kerana pelbagai medium dan bahan pembelajaran terkandung di dalam Google Classroom seperti nota, video serta soalan berbentuk interaktif yang membantu mereka meningkatkan pencapaian mata pelajaran Sains. Item ketiga yang menunjukkan peratusan kedua tertinggi adalah pembelajaran dalam talian membantu berinteraksi secara berkesan dengan rakan iaitu sebanyak $87 \%$. Peratusan ini tinggi disebabkan oleh naluri murid itu sendiri yang suka berinteraksi bersama rakan menyebabkan mereka bersetuju dengan item berkenaan.

Seterusnya item "pembelajaran dalam talian adalah menyeronokkan" menjadi penyumbang keempat tertinggi dengan $83 \%$ murid bersetuju dengan kenyataan ini. Ini di sebabkan murid suka mendalami dan menggunakan teknologi baru seperti pembelajaran dalam talian menyebabkan mereka teruja. Item lain seperti "Saya mudah bertanya dengan guru dengan menggunakan pembelajaran dalam talian" juga menunjukkan peratusan yang tinggi. Ini membuktikan, pembelajaran dalam talian bukanlah halangan bagi murid untuk berinteraksi dengan guru

\section{Analisa kemahiran literasi Sains murid}

Untuk mengenal pasti kemahiran literasi Sains murid, satu borang senarai semak telah diedarkan kepada guru untuk membuat penilaian setelah intervensi kajian dijalankan. Terdapat 10 item soalan yang terkandung dalam borang senarai semak. Pengkaji kemudiannya menganalisis data dalam bentuk 
frekuensi dan peratusan. Jadual 2 di bawah menunjukkan nilai frekuensi dan peratusan bagi setiap item yang terlibat.

Jadual 2: Analisis kemahiran literasi Sains murid setelah menjalani intervensi

\begin{tabular}{|c|c|c|c|}
\hline Item & Perkara & Ya & Tidak \\
\hline & Semasa menjalankan aktiviti pembelajaran Sains & 16 & 14 \\
\hline 1 & $\begin{array}{l}\text { adakah murid-murid menunjukkan minat untuk } \\
\text { mempelajari Sains? }\end{array}$ & $53 \%$ & $47 \%$ \\
\hline & Adakah murid-murid mengambil peluang & 22 & 8 \\
\hline 2 & menerokai pembelajaran Sains? & $73 \%$ & $27 \%$ \\
\hline & Adakah murid boleh menjawab soalan ketika sesi & 25 & \\
\hline 3 & pengajaran dan pembelajaran dijalankan? & $83 \%$ & $17 \%$ \\
\hline 4 & Semasa sesi pembelajaran Sains adakah murid & 18 & 12 \\
\hline 4 & menunjukkan minat untuk belajar Sains? & $60 \%$ & $40 \%$ \\
\hline & Semasa melakukan aktiviti penyiasatan Sains & 19 & 11 \\
\hline 5 & $\begin{array}{l}\text { adakah murid menggunakan pengetahuan sedia } \\
\text { ada mereka? }\end{array}$ & $63 \%$ & $37 \%$ \\
\hline & Sebelum aktiviti pembelajaran Sains. Adakah & 29 & 1 \\
\hline 0 & murid kelihatan bosan dan malas? & $97 \%$ & $3 \%$ \\
\hline & Dalam aktiviti pembelajaran Sains adakah murid & 24 & 6 \\
\hline 7 & $\begin{array}{l}\text { menyertai sesi soal jawab yang dikemukakan oleh } \\
\text { guru? }\end{array}$ & $80 \%$ & $20 \%$ \\
\hline & Adakah murid berinteraksi bersama rakan mereka & 17 & 13 \\
\hline 8 & $\begin{array}{l}\text { ketika pengajaran dan pembelajaran sains } \\
\text { dilaksanakan? }\end{array}$ & $57 \%$ & $43 \%$ \\
\hline 9 & Adakah murid faham konsep Sains yang & 19 & 11 \\
\hline & dipelajari? & $63 \%$ & $37 \%$ \\
\hline & Adakah murid menghayati dan bersedia untuk & 29 & 1 \\
\hline & sesi pembelajaran Sains pada sesi akan datang? & $97 \%$ & $3 \%$ \\
\hline $\mathrm{Ke}$ & eluruhan & $73 \%$ & $27 \%$ \\
\hline
\end{tabular}

Bagi senarai item yang mempunyai nilai peratusan paling tinggi adalah dicatat dalam item 10 iaitu 97\% murid untuk menghayati dan bersedia untuk sesi pembelajaran Sains pada sesi akan datang. Ini adalah kerana melalui hasil pemerhatian penyelidik pelajar didapati kelihatan bersemangat dan mempunyai motivasi yang tinggi untuk mengikuti proses pembelajaran yang melibatkan penggunaan ICT di dalam pembelajaran subjek Sains. Oleh itu, keadaan sebegitu mendorong pelajar untuk menunjukkan sikap yang baik di sepanjang proses pembelajaran dijalankan.

Item 2 juga mencatatkan peratusan yang tinggi dimana 83\% murid mengambil peluang menerokai pembelajaran Sains sepanjang pembelajaran secara dalam talian. Selain itu, item 7 mencatatkan peratusan yang tinggi iaitu sebanyak $80 \%$ murid terlibat aktif semasa sesi soal jawab yang dikemukakan oleh guru.

\section{Analisa kesan pembelajaran berasaskan inkuiri terhadap pencapaian Sains murid secara dalam talian}

Untuk mengkaji kesan pembelajaran inkuiri terhadap pencapaian Sains murid, pengkaji telah menganalisis data murid secara deskriptif dan inferensi. Data deskriptif dalam bentuk peratusan diperincikan dalam Jadual 3. 
DOI: https://doi.org/10.47405/mjssh.v7i1.1250

Jadual 3: Data analisis deskriptif ujian pra dan ujian pasca pencapaian Sains

\begin{tabular}{|c|c|c|c|}
\hline Pelajar & $\begin{array}{c}\text { Ujian Pra } \\
(\mathbf{1 0 0 \%})\end{array}$ & $\begin{array}{c}\text { Ujian Pasca } \\
(100 \%)\end{array}$ & $\begin{array}{c}\text { Perbezaan } \\
\text { (Pasca-Pra) }\end{array}$ \\
\hline P1 & 57.5 & 82.5 & 25.0 \\
\hline $\mathrm{P} 2$ & 65 & 70 & 5.0 \\
\hline P3 & 75 & 82.5 & 7.5 \\
\hline P4 & 80 & 82.5 & 2.5 \\
\hline P5 & 75 & 72.5 & -2.5 \\
\hline P6 & 87.5 & 90 & 2.5 \\
\hline P7 & 62.5 & 75 & 12.5 \\
\hline P8 & 72.5 & 85 & 12.5 \\
\hline P9 & 60 & 82.5 & 22.5 \\
\hline P10 & 85 & 92.5 & 7.5 \\
\hline P11 & 75 & 82.5 & 7.5 \\
\hline P12 & 70 & 85 & 15 \\
\hline P13 & 55 & 65 & 10 \\
\hline P14 & 82.5 & 85 & 2.5 \\
\hline $\mathrm{P} 15$ & 77.5 & 82.5 & 5 \\
\hline P16 & 77.5 & 80 & 2.5 \\
\hline P17 & 65 & 90 & 25 \\
\hline P18 & 60 & 75 & 15 \\
\hline P19 & 82.5 & 90 & 7.5 \\
\hline $\mathrm{P} 20$ & 62.5 & 82.5 & 20 \\
\hline $\mathrm{P} 21$ & 55 & 65 & 10 \\
\hline $\mathrm{P} 22$ & 75 & 82.5 & 7.5 \\
\hline $\mathrm{P} 23$ & 70 & 80 & 10 \\
\hline $\mathrm{P} 24$ & 67.5 & 82.5 & 15 \\
\hline $\mathrm{P} 25$ & 75 & 80 & 5 \\
\hline P26 & 67.5 & 75 & 7.5 \\
\hline P27 & 80 & 85 & 5 \\
\hline $\mathrm{P} 28$ & 70 & 77.5 & 7.5 \\
\hline P29 & 82.5 & 87.5 & 5 \\
\hline P30 & 75 & 92.5 & 17.5 \\
\hline Min & 71.5 & 81.3 & - \\
\hline
\end{tabular}

Berdasarkan analisis markah ujian pra, markah terendah dicatatkan oleh P13 dan P21 iaitu sebanyak 55\% dan markah tertinggi dicatat oleh P6 iaitu markah masing-masing sebanyak 87.5.5\%. Manakala bagi ujian pos pula, markah terendah dicatatkan oleh P2 iaitu sebanyak $72 \%$ dan markah tertinggi pula dicatat oleh P10 dan P30 iaitu masing-masing mencatat markah 92.5\%.

Seramai 29 orang responden menunjukkan peningkatan markah di dalam pencapaian selepas menjalani intervensi. Peningkatan tertinggi dicatatkan oleh P1 iaitu sebanyak 25\% manakala kedua tertinggi dicatatkan oleh P9 iaitu sebanyak 22.5\%. Walau bagaimanapun, terdapat seorang responden yang mengalami penurunan markah iaitu dicatat oleh P5 dengan penurunan markah sebanyak $2.5 \%$.

Selain analisis deskriptif dijalankan ke atas ujian pencapaian, penyelidik juga telah menjalankan analisis inferensi bertujuan untuk melihat sama ada wujud perbezaan signifikan terhadap min markah dengan di antara ujian pra dan ujian pos terhadap responden setelah menjalani intervensi pembelajaran dengan menggunakan Google Classroom. Analisis inferensi yang digunakan adalah melalui ujian penormalan dan ujian-t sampel berpasangan. 
DOI: https://doi.org/10.47405/mjssh.v7i1.1250

Jadual 4: Dapatan Ujian Pernomalan ujian pra dan ujian pasca

\begin{tabular}{lllllll}
\hline \multicolumn{3}{l}{ Kolmogorov-Smirnov } & \multicolumn{4}{l}{ Shapiro-Wilk } \\
\hline & Statistic & df & Sig. & Statistic & df & Sig. \\
Ujian_Pra & .150 & 30 & .082 & .964 & 30 & .392 \\
Ujian_Pasca & .199 & 30 & .004 & .932 & 30 & .057 \\
\hline
\end{tabular}

Disebabkan sampel dalam kajian ini kecil $(<50)$, maka nilai $p$ dilihat dari nilai ujian KolmogorovSmirnov. Nilai $p$ bagi ujian pra adalah bertaburan normal dimana $p>.05$, namun data bagi ujian pasca bertaburan tidak normal dimana $p<.05$. Melihat kepada keadaan ini, pengkaji menjalankan semula ujian penormalan dengan melihat kepada skor perbezaan ujian pasca berbanding ujian pra. Jadual 5 menunjukkan dapatan ujian pernomalan bagi skor perbezaan ujian pasca dan ujian pra.

Jadual 5: Dapatan Ujian Pernomalan ujian pra dan ujian pasca

\begin{tabular}{lllllll}
\hline & \multicolumn{2}{l}{ Kolmogorov-Smirnov } & \multicolumn{3}{l}{ Shapiro-Wilk } \\
\hline & Statistic & df & Sig. & Statistic & df & Sig. \\
Skor & .198 & 30 & .004 & .926 & 30 & .038 \\
perbezaan & & & & & & \\
$\begin{array}{l}\text { Ujian_Pasca } \\
\text { dan }\end{array}$ & & & & & & \\
Ujian_Pra & & & & & & \\
\hline
\end{tabular}

Dapatan ujian penormalan mendapati data skor perbezaan pra dan pasca adalah betaburan tidak normal dimana $p<.05$. Maka, pengkaji menjalankan ujian Wilcoxon Signed Rank bagi melihat perbezaan min antara ujian pra dan pasca. Jadual 6 dan Jadual 7 menunjukkan data analisis bagi ujian Wilcoxon signed rank.

Jadual 6: Statistik Ranks ujian pra dan ujian pasca

\begin{tabular}{lllll}
\hline & $\mathbf{N}$ & Mean Rank & Sum of Ranks \\
\hline pasca - pra & Negative Ranks & $1^{\mathrm{a}}$ & 3.00 & 3.00 \\
& Positive Ranks & $29^{\mathrm{b}}$ & 15.93 & 462.00 \\
& Ties & $0^{\mathrm{c}}$ & & \\
& Total & 30 & & \\
\hline
\end{tabular}
a. Ujian pasca $<$ Ujian pra
b. Ujian pasca > Ujian pra
c. Ujian pasca $=$ Ujian Pra

Jadual 7: Ujian Wilcoxon Signed Rank pencapaian Sains

\begin{tabular}{ll}
\hline & pasca - pra \\
\hline$Z$ & $-4.734 \mathrm{~b}$ \\
Asymp. Sig. (2-tailed) & .000 \\
\hline
\end{tabular}

a. Wilcoxon Signed Ranks Test

b. Based on negative ranks.

Hasil dari ujian Wilcoxon Signed Ranks menunjukkan terdapatnya perbezaan yang signifikan antara ujian pra dan pasca $(p<.05)$. Secara tidak langsung ianya membuktikan bahawa pembelajaran berasaskan inkuiri secara dalam talian memberikan impak yang positif terhadap pencapaian Sains murid. 


\section{Perbincangan Kajian}

Dapatan kajian menunjukkan bahawa tahap kesediaan murid untuk pembelajaran secara dalam talian adalah memuaskan dimana majoriti murid bersetuju pembelajaran dalam talian dapat membantu mereka dalam meningkatkan pencapaian dalam topik yang dipelajari. Malah latihan yang diberikan oleh guru secara dalam talian membantu pemahaman mereka dalam pembelajaran. Antara salah satu faktor yang menyumbang kepada keadaan ini adalah dimana murid telah didedahkan dengan persekitaran pembelajaran secara dalam talian sejak satu tahun yang lalu, sejurus selepas pandemik COVID-19 melanda negara. Segala aktiviti P\&P yang dahulunya diberikan oleh guru secara bersemuka telah digantikan secara maya. Dengan penggunaan teknologi, terbukti proses pengajaran masih boleh berjalan seperti biasa. Teknologi antara lain memainkan peranan dalam proses P\&P, antaranya ianya dapat menarik minat murid kerana praktikal dalam keadaan yang tidak memungkinkan guru dan murid untuk bersua muka. Dapatan ini selari dengan dapatan dari kajian yang dilakukan oleh Berk (2009) yang menyatakan bahawa pengajaran melalui teknologi dapat menarik tumpuan, meningkatkan motivasi serta memberikan pengalaman pembelajaran yang bermakna kepada murid.

Hasil dari pemerhatian yang dijalankan oleh pengkaji, terbukti bahawa majoriti murid mempunyai kemahiran literasi Sains sewaktu sesi pembelajaran secara dalam talian. Hasil pemerhatian mendapati, murid dapat memahami konsep Sains hasil dari aktiviti pembelajaran inkuiri secara dalam talian. Keinginan mereka untuk meneroka topik pembelajaran Sains juga dapat dilihat sewaktu pemerhatian dijalankan. Sesi pembelajaran menjadi satu sesi yang menyeronokkan apabila murid terlibat secara aktif melalui interaksi antara rakan-rakan. Perbincangan secara dalam talian sedikit sebanyak merapatkan jurang interaksi sesama rakan. Selain itu, pencapaian murid dalam pembelajaran berasaskan inkuiri secara dalam talian juga menunjukkan perubahan yang positif. Ini berkemungkinan hasil dari pendekatan atau strategi pembelajaran berasaskan inkuiri yang disuntik semasa proses pembelajaran. Hal ini dipersetujui oleh Jamian dan Ismail (2013) yang menyatakan bahawa pendekatan pedagogi yang bersesuaian yang diterapkan dalam pembelajaran mampu untuk menyediakan suasa pembelajaran yang berkualiti.

\section{Kesimpulan}

Kajian ini membuktikan, pelaksanaan strategi atau kaedah pembelajaran yang bersesuaian, terbukti dapat meningkatkan mutu dan kualiti pembelajaran. Dalam konteks kajian ini, pembelajaran berasaskan inkuiri secara dalam talian terbukti memberikan impak yang positif kepada murid terutamanya bagi penyampaian topik-topik pembelajaran dalam subjek Sains. Hasil daripada kajian ini juga diharapkan dapat dijadikan panduan oleh guru untuk membuat aktiviti pembelajaran yang inovatif dan menarik agar murid merasai pengalaman pembelajaran secara dalam dengan lebih bermakna.

\section{Rujukan}

Atkinson, M. P., \& Hunt, A. N. (2008). Inquiry-guided learning in Sociology. Teaching Sociology, 36 (1), 1 - 7.

Baybee, R.W, Taylor, J.A., Gardner, A., Scotter, P.V., Powell, J.C., Westbrook, A., \& Landes, N. (2006). The BSCS 5E Instructional Model: Origins, Effectiveness and Applications. Colorado Springs: BSCS

Berk, R. A. (2009). Multimedia teaching with video clips: TV, movies, YouTube, and mtvU in the college classroom. International Journal of Technology in Teaching and Learning, 5(1), 1-21.

Ganesan, S., Balakrishnan, P., Ariffin, K., Kannan, B. \& Manimaran, V. (2020). Inquiry method in the teaching and learning process. Shanlax International Journal of Education, 8(3), 6-9.

Hmelo-Silver, C., Duncan, R. G., \& Chinn, C. A. (2007). Scaffolding and achievement in problembased and inquiry learning: a response to Kirschner, Sweller, and Clark (2006). Educational Psychologist, 42, 99-107.

Huba, M. E., \& Freed, J. E. (2000). Learner-centered assessment on college campuses: shifting the focus from teaching to learning. Boston: Allyn and Bacon. 
Jamian, A. R., \& Ismail, H. (2013). Pelaksanaan pembelajaran menyeronokkan dalam pengajaran dan pembelajaran Bahasa Melayu. Jurnal Pendidikan Bahasa melayu (JPBM), 3(2), 49-63

Maidin Shah, H., 2004. Kesan kaedah pengajaran metakognisi-inkuiri terhadap prestasi dalam matematik dan penaakulan saintifik di kalangan pelajar diploma. Universiti Teknologi Mara: Tesis Ph.D

Maria C.A., Samsilah R., \& Tajularipin S. (2014). Strategi pengajaran pembelajaran di institusi pengajian tinggi: Satu anjakan paradigma. Malaysian Education Dean Council Journal. 8, 101-115

McLoughlin, M. (2009). Incorporating inquiry-based learning in the calculus sequence: A most challenging endeavour. Paper presented at the Annual Joint Meetings of the American Mathematical Society \& the Mathematical Association of America. Washington, DC

Nor Puteh, S., \& Nawastheen, F. M. (2013). An evaluation on the implementation of 5E instructional model in teaching geography in Sri Lanka. Middle-East Journal of Scientific Research, 16(5), 721-728

Nordin, N. \& Daud, M. Y. (2020). Level of readiness of daily secondary school students for use of augmented reality in form 2 Science textbooks. Universal Journal of Educational Research, 8 (11A), $17-24$.

Prayogi, S., Yuanita, L. \& Wasis. (2018). Critical Inquiry based learning: A model of learning to promote critical thinking among prospective teachers of Physics. Journal of Turkish Science Education, 15(1), 43-56.

Raja Ismail, R. A. \& Ismail, D. (2018). Aplikasi 'konsep 4C' pembelajaran abad ke-21 dalam kalangan guru pelatih pengajian agama Institut Pendidikan Guru Kampus Dato' Razali Ismail. Asian People Journal (APA), 1(1), 45-65.

Rozali, N. A. \& Abd Halim, N. D. (2020). Kesan pembelajaran berasaskan inkuiri dengan integrasi video terhadap pencapaian pelajar dalam pembelajaran Matematik. Innovative Teaching and Learning Journal, 3(2), 42-60.

Sidek, S. \& Hashim, M. (2016). Pengajaran berasaskan video dalam pembelajaran berpusatkan pelajar: analisis dan kajian kritikal. Journal of ICT in Education. 3, 24-33.

Summerlee, A., \& Murray, J. (2010). The impact of inquiry-based learning on academic performance and student engagement. Journal of Higher Education, 40(2), 78-94.

Umar, I. N. \& Maswan, S. (2007). The effects of a web-based guided inquiry approach on students' achievement. Journal of Computer. 2(5), 38-43.

Yaumi, Wisanti \& Admoko, S. (2017). Penerapan perangkat model discovery learning pada materi pemanasan global untuk melatihkan kemampuan literasi sains mahasiswa SMP kelas VII". EJournal Pensa FMIPA UNESA, 5(1).

Zhao, N., Wardeska, J.G., McGuire, S.Y., \& Cook, E. (2014). Metacognition: an effective tool to promote success in college science learning. Journal of College Science Teaching, 43 (4), 48-54. 